\title{
Invocations and Intoxication: Does Prayer Decrease Alcohol Consumption?
}

Nathaniel M. Lambert

Florida State University

Frank D. Fincham

Florida State University

Loren D. Marks

Brigham Young University - Provo, loren_marks@byu.edu

Tyler F. Stillman

Florida State University

Follow this and additional works at: https://scholarsarchive.byu.edu/facpub

Part of the Other Social and Behavioral Sciences Commons

\section{Original Publication Citation}

Lambert, N. M., Fincham, F. D., Marks, L. D., \& Stillman, T. F. (2010). Invocations and intoxication: Does prayer decrease alcohol consumption? Psychology of Addictive Behaviors, 24, 209-219.

\section{BYU ScholarsArchive Citation}

Lambert, Nathaniel M.; Fincham, Frank D.; Marks, Loren D.; and Stillman, Tyler F., "Invocations and Intoxication: Does Prayer Decrease Alcohol Consumption?" (2010). Faculty Publications. 4912. https://scholarsarchive.byu.edu/facpub/4912 accepted for inclusion in Faculty Publications by an authorized administrator of BYU ScholarsArchive. For more information, please contact ellen_amatangelo@byu.edu. 


\title{
Invocations and Intoxication: Does Prayer Decrease Alcohol Consumption?
}

\author{
Nathaniel M. Lambert and Frank D. Fincham \\ Florida State University
}

\author{
Loren D. Marks \\ Louisiana State University
}

Tyler F. Stillman

Florida State University

\begin{abstract}
Four methodologically diverse studies $(N=1,758)$ show that prayer frequency and alcohol consumption are negatively related. In Study $1(n=824)$, we used a cross-sectional design and found that higher prayer frequency was related to lower alcohol consumption and problematic drinking behavior. Study 2 $(n=702)$ used a longitudinal design and found that more frequent prayer at Time 1 predicted less alcohol consumption and problematic drinking behavior at Time 2, and this relationship held when controlling for baseline levels of drinking and prayer. In Study $3(n=117)$, we used an experimental design to test for a causal relationship between prayer frequency and alcohol consumption. Participants assigned to pray every day (either an undirected prayer or a prayer for a relationship partner) for 4 weeks drank about half as much alcohol at the conclusion of the study as control participants. Study $4(n=115)$ replicated the findings of Study 3, as prayer again reduced drinking by about half. These findings are discussed in terms of prayer as reducing drinking motives.
\end{abstract}

Keywords: prayer, alcohol, problematic drinking

Religious involvement is prevalent in the United States. Survey research shows that $92 \%$ of Americans believe in God (U.S. Religious Landscape Survey, 2008). Alcohol consumption is also widespread among Americans, and especially among U.S. college students, of whom approximately $85 \%$ consume alcohol (O'Malley \& Johnston, 2002). Yet, religious beliefs and alcohol consumption coexist uneasily in American culture; many religions urge refraining from drinking and drunkenness, and drinking and drunkenness often result in decidedly unreligious behavior. In the present investigation, we sought to uncover the relationship between religious or spiritual behaviors and alcohol consumption, with the expectation that religious or spiritual behaviors would be associated with a decrease in alcohol consumption. This is a surprisingly understudied area of research given the serious consequences of excessive alcohol consumption and the negative relationship between religiosity and alcohol (Benda, Pope, \& Kelleher, 2006; Gorsuch, 1995; Gartner, Larson, \& Allen, 1991; Humphreys \& Gifford, 2006; Johnson, Sheets, \& Kristeller, 2008; Koenig, McCollough, \& Larson, 2001; Miller, 1998).

The current investigation proceeds as follows. We first illustrate why alcohol consumption among college students is an important target of inquiry by discussing some of the negative consequences of excessive alcohol consumption in this age group. Then, we

Nathaniel M. Lambert and Frank D. Fincham, Department of Family and Child Sciences, Florida State University; Tyler F. Stillman, Department of Psychology, Florida State University; Loren D. Marks, Family, Child, and Consumer Sciences, Louisiana State University.

Correspondence concerning this article should be addressed to Nathaniel M. Lambert, Family Institute, Sandels Building, Florida State University, Tallahassee, FL 32306. E-mail: nlambert@fsu.edu describe the theoretical basis for our expectations regarding why religion and spirituality should affect alcohol consumption. Finally, we describe the limitations of prior research, explain our rationale for targeting the practice of prayer, and offer an overview of the studies.

\section{Consequences of Excessive Alcohol Consumption}

For at least a decade, alcohol abuse has been cited by many health researchers as among the most serious threats to health in the United States (Burger \& Youkeles, 2000; Kapner, 2008). The dangers of alcohol abuse are especially pronounced among college-age young adults (Wechsler \& Nelson, 2008). Between $40 \%$ and $44 \%$ of American college students engage in heavy drinking on at least a biweekly basis (O’Malley \& Johnston, 2002), resulting in a wide array of negative consequences (for a review, see Perkins, 2002), including using illegal drugs (Jones, Oeltmann, Wilson, Brener, \& Hill, 2001; cf. Fenzel, 2005), having multiple sex partners (Arasteh, Des Jarlais, \& Perlis, 2008; Cooper, 2002), engaging in unprotected sex (Hingson, Heeren, Winter, \& Wechsler, 2003; Kapner, 2008; Mathias \& Turrentine, 2003), participating in extradyadic sexual behavior (Graham, Fincham, \& Lambert, 2009), and experiencing sexual assault (Abbey, 2002; MohlerKuo, Dowdall, \& Koss, 2005). Up to 600,000 college students a year nationally are hit or assaulted by a drinking student (Hingson, Heeren, Winter, \& Wechsler, 2005) and approximately 1,700 college students die annually from alcohol-related causes (Kapner, 2008). In sum, excessive alcohol consumption is related to myriad negative outcomes for young adults. Given the serious consequences of excessive alcohol consumption, understanding potential protective factors should be a priority. Religiosity and spirituality, and specifically prayer, may be important protec- 
tive factors of excessive alcohol consumption and merit a closer examination.

\section{Religiosity, Spirituality, and Alcohol Consumption}

Most world religions provide governing principles concerning the sanctity of one's mental, physical, and spiritual well-being (Worthington, 1993), including self-control and personal virtue (Regnerus, 2003). A meta-analysis found that religiosity and unlawful behavior were negatively related, with a moderate effect of -.12 across 60 recent studies (Baier \& Wright, 2001). Thus, it seems plausible that religiosity would influence alcohol consumption. Indeed, higher levels of religiosity and spirituality are typically (among studies using nonexperimental designs) related to lower alcohol consumption and to fewer problems connected to alcohol use (Benda et al., 2006; Gorsuch, 1995; Gartner et al., 1991; Humphreys \& Gifford, 2006; Johnson et al., 2008; Koenig et al., 2001; Miller, 1998). Other research shows that even conservative Protestants (the denomination with the highest risk for alcohol dependence) have a $40 \%$ lower risk of dependence than those with no religious affiliation (Hilton, 1991). Another study found that the practices of private prayer and scripture study were related to lower risk of alcohol use disorders (Koenig, George, Meador, Blazer, \& Ford, 1994).

However, two experimental studies found that substance abusers randomly assigned to a spiritual guidance intervention did not report a reduction in use compared with those who received treatment as usual (Miller, Forcehimes, O'Leary, \& LaNoue, 2008). And another study found that praying for patients with substance abuse by volunteers did not have an effect on patients' alcohol consumption, although prayer by the patients themselves was related to lower rates of drinking (Walker, Tonigan, Miller, Corner, \& Kahlich, 1997).

High spirituality and religiousness most often appears to be associated with lower alcohol consumption and alcohol-related problems, but why might this be the case? One possibility may be that prayer can be an alternative form of coping. Religion or spirituality may, in some instances, satisfy some of these motivations, thus reducing the motivation to drink (Cooper, 1994). Religiosity or spirituality may be an alternative source people can turn to to cope with life's challenges, thus mitigating the motivation to use alcohol to cope. Some research indicates that drinking is a common means of coping, especially among college students (Park \& Levenson, 2002). Coping with perceived lack of meaning or connection to God may be another reason for using substances like alcohol (e.g., Piedmont, 2004). Religion or spirituality may fill this void and help people cope with difficult life events. Pargament (1997) suggested that common religious beliefs can be used for coping during stressful life events. Religion may be instrumental in restoring beliefs (during challenging times) that the world is predictable, fair, safe, given that a benevolent God is in charge (Dull \& Skokan, 1995; Pargament, 1997).

Furthermore, several scholars have stressed the importance of praying as a coping process (Carver, Scheier, \& Weintraub, 1989; Folkman, Lazarus, Dunkel-Schetter, DeLongis, \& Gruen, 1986; Pargament, 1997; Parker \& Brown, 1982). However, not all research suggests that the effects of coping through prayer are positive. Lawson, Reesor, Keefe, and Turner (1990) found that prayer was associated with coping with challenges through mental distraction, which is not likely to be an effective form of coping. Thus, it seems plausible that religious participation, spirituality, and prayer may provide an alternative means for coping, thereby diminishing the need to turn to alcohol for this purpose. Again, prayer seems to be very relevant to the coping aspect of the motivational model for drinking. We describe below some of the limitations of prior research and why longitudinal and experimental methods are needed to test this association as well as our rationale for targeting prayer as a means of testing our hypothesis that religion and spirituality reduce alcohol consumption.

\section{Limitations of Prior Research}

Several obstacles exist in the current literature on religion and physical health that limit its scope and preclude important inferences from being made. First, given the prior reliance on correlational data, it is nearly impossible to determine whether specific religious or spiritual behaviors cause the positive outcomes mentioned in the literature, or whether the spiritual behaviors are the result of positive outcomes.

Second, making inferences from the current studies on religious influence is plagued by plausible third-variable explanations. For example, even though Townsend, Kladder, Ayele, and Mulligan (2002) found a link between religiosity and depression, it could be that the more expansive social networks found among religious participants (Ellison \& George, 1994; Joiner, Perez, \& Walker, 2002; Taylor, Chatters, \& Levin, 2004) actually accounts for the association, rather than any specific religious behaviors per se.

How can these serious limitations be addressed? One possible solution to better determine the effect of religious or spiritual behaviors on important outcome variables is through use of experimental designs. Of course, ethical and practical considerations preclude the random assignment of religion, thereby creating a puzzling dilemma for generating scientifically sound research in an area that affects a large majority of Americans. Our solution is to investigate prayer.

\section{Prayer}

Prayer is a form of religious or spiritual activity common to all the "Abrahamic" traditions (i.e., Judaism, Christianity, and Islam) and has strong parallels in other religious traditions (e.g., Buddhism, Hinduism, and Shinto). Approximately $90 \%$ of Americans pray at least occasionally (McCullough \& Larson, 1999). Prayer may be perceived as both a religious activity — as it plays a central role in most religious ceremonies and worship — and a spiritual activity - as a person disconnected from organized religion may pray frequently in a private place. Prayer is an ideal target for experimental research because the frequency and content of prayers may be manipulated. Also, prayer may be practiced individually, which can reduce the chance that findings simply reflect the common third-variable problem of religious social networks. In the present investigation, we used a diverse set of methods, including experiments, to assess the relationship between prayer and drinking. Our intent was to proceed in a way that would rule out selection bias and the third-variable problems common to research on religion. Although some experimental research has focused on the effect of one person's prayer on the physical health of another (for a review, see Masters \& Spielmans, 2007), examination of the 
effects of prayer on one's own behavior has surprisingly been left virtually unexplored. Also, although the "Serenity Prayer" (and many other prayers) has functioned as an important part of 12-step programs for decades (which has been shown to reduce alcohol dependence; e.g., Chappel \& DuPont, 1999; Ouimette, Finney, \& Moos 1997), it remains unclear whether the prayer component of such interventions is an active element of the intervention that contributes to efficacy, and whether prayer can be helpful in preventing alcoholism or reducing risk factors for alcoholism.

\section{Overview of Studies}

The current studies tested the hypothesis that increasing prayer frequency reduces alcohol consumption and the attending problematic behavior related to alcohol consumption using a variety of methods. We first sought to establish whether there was a relationship between prayer and alcohol consumption and problematic drinking both concurrently and across time. We then tested whether there is a causal relation between prayer and alcohol consumption, and in doing so attempted to rule out self-selection bias and third-variable alternative explanations.

Study 1 was an initial test of our hypothesis and examined whether higher prayer frequency was negatively related to total alcohol consumption and problematic drinking behavior. We hypothesized that greater prayer frequency would be related to lower alcohol consumption and problematic drinking, even when controlling for variables associated with alcohol consumption: sex, age, and social desirability. Study 2 used a longitudinal design, with the expectation that high initial prayer frequency would predict lower alcohol consumption and problematic drinking 3 months later, even when controlling for sex, age, and social desirability. The longitudinal design also permitted us to test whether alcohol consumption affects prayer. Finally, Studies 3 and 4 used experimental designs to test causal hypotheses and to rule out self-selection bias as a third-variable alternative explanation. We predicted that participants randomly assigned to pray every day for 4 weeks would report lower alcohol consumption than control participants, even when controlling for baseline prayer frequency and alcohol consumption.

\section{Study 1}

The objective of Study 1 was to determine whether higher prayer frequency would correspond to less alcohol consumption and lower rates of problematic drinking behavior. Prior research has found that men drink more alcohol than women (Johnston, O'Malley, Bachman, \& Schulenberg, 2007), that alcohol use tends to increase during young adulthood (Weitzman, Nelson, \& Wechsler, 2003), and that reporting of religious behavior is subject to socially desirable responding (Hadaway, Marler, \& Chavez, 1993). Thus, we controlled for all three of these variables-sex, age, and social desirability-to reduce spurious association. We hypothesized that greater prayer frequency would be related to lower levels of alcohol consumption and problematic drinking behavior.

\section{Method}

Participants. Undergraduates $(N=824 ; 673$ women $)$ participated in the study for partial course credit. Participants ranged in age from 18 to 38 years, with a median age of 19 . Seventy-two percent of the participants were Caucasian, $10 \%$ were African American, 9\% were Hispanic, and the remaining $9 \%$ reported other races. Thirty-four percent of participants were freshmen, $32 \%$ were sophomores, $26 \%$ were juniors, and $8 \%$ were seniors.

Measures.

Prayer. Prayer was assessed with a three-item measure that included the following items: "I pray daily," "I pray before I go to sleep," "I usually say a prayer before each meal." These items were answered on a 5-point scale ranging from strongly agree to strongly disagree. Coefficient alpha was .86 for the current sample.

Alcohol consumption index. Total alcohol consumption was assessed by using an alcohol index in which participants are asked, "Within the last 30 days, on how many days did you have a drink containing alcohol?" and then asked, "How many drinks containing alcohol did you have on a typical day when you were drinking?" Multiplying the two responses yielded the commonly used quantity-frequency index used in research on substance use (see Dawson \& Room, 2000).

Problematic drinking behavior. To assess problematic drinking, we administered the College Alcohol Problems ScaleRevised. This eight-item scale taps how often people experience negative consequences of drinking (O'Hare, 1997). Participants indicated how often over the previous 4 months they had, for example, driven a vehicle under the influence or had problems with appetite or sleeping as a result of alcohol use. In the current sample, coefficient alpha was .83 .

Social desirability. A shortened, 10-item version of the Marlowe-Crowne Social Desirability Scale (Reynolds, 1982) was used to assess the tendency to present oneself in a socially desirable manner. Responses were coded so that higher scores reflected a greater tendency toward socially desirable responding. Reliability was not computed because this measure more closely resembles an index than a scale.

\section{Results}

Prayer and total alcohol consumption. To examine the hypothesis that more prayer predicts lower total alcohol scores, we computed a regression equation in which the control variables of sex, age, and social desirability were entered at Step 1 and prayer frequency was entered at Step 2. Consistent with predictions, higher prayer frequency scores were negatively related to total alcohol consumption scores, even when controlling for sex, age, and social desirability $(\beta=-.20, p<.01)$. For full results, see Table 1.

Prayer and problematic drinking behavior. To examine the hypothesis that more prayer would be negatively related to problematic drinking behavior, we computed a regression equation in which we again controlled for the variables of sex, age, and social desirability by entering them at Step 1 and entering prayer frequency at Step 2. Consistent with predictions, higher prayer frequency scores were negatively related to problematic drinking scores, even when controlling for sex, age, and social desirability $(\beta=-.20, p<.01)$. For full results, see Table 2 . 
Table 1

Summary of Hierarchical Regression Analysis for Variables Predicting Total Alcohol Consumption Scores $(N=828)$

\begin{tabular}{lrrrr}
\hline \multicolumn{1}{c}{ Variable } & \multicolumn{1}{c}{ B } & SE $B$ & $\beta$ & $p$ \\
\hline Step 1 & & & & \\
$\quad$ Sex & -13.29 & 3.17 & -.14 & .00 \\
$\quad$ Age & 0.99 & 0.74 & .05 & .18 \\
$\quad$ Social desirability & -1.61 & 0.61 & -.09 & .01 \\
Step 2 & & & & \\
$\quad$ Prayer frequency & -2.03 & 0.34 & -.20 & .00 \\
\hline
\end{tabular}

Note. $R^{2}=.04$ for Step $1(p<.01) ; \Delta R^{2}=.04$ for Step $2(p<.01)$. Sex was coded so that $1=$ male and $2=$ female.

\section{Discussion}

These results are consistent with our hypothesis as prayer frequency was negatively related to total alcohol consumption and problematic drinking behavior, even when controlling for sex, age, and social desirability. However, the current study is somewhat limited in that we assessed participants' scores at only one time point, which provides limited information regarding the direction or stability of this relationship over time. We addressed this limitation in Study 2 by examining the same variables in a new sample, this time using a longitudinal design.

\section{Study 2}

Study 2 tested whether the relationships found in Study 1 would persist over time, again controlling for sex, age, and social desirability. The longitudinal design allows for some inference as to the direction of effects. We used a cross-lagged stability model to determine whether initial prayer would predict later alcohol consumption and problematic drinking behaviors, but not vice versa. We collected baseline responses at the beginning of the academic semester and then collected follow-up measures 3 months later at the end of the academic semester.

\section{Method}

Participants and measures. Undergraduates $(N=702)$ participated in the study for partial course credit; however, 59 failed to complete relevant measures at Time 2. Thus, 643 undergraduates (505 women) were included in the analyses. Participants ranged in age from 17 to 27 years, with a median age of 19 . Seventy percent of the participants were Caucasian, $13 \%$ were African American, 9\% were Hispanic, and the remaining 8\% reported other races. Twenty-four percent of participants were freshmen, $45 \%$ were sophomores, $24 \%$ were juniors, and $7 \%$ were seniors. Measures of prayer (Study 2, Time 1: $\alpha=.83$; Study 1, Time 1: $\alpha=.86$ ), problematic drinking (Study 2, Time 1: $\alpha=.84$; Study 1, Time 1: $\alpha=.86$ ), alcohol consumption, and social desirability were identical to those used in Study 1.

\section{Results}

Attrition. We compared the Time 1 scores of those individuals who dropped out of the study with those who persisted in the study to ensure that any observed effect was not a function of attrition. For example, if participants who drank more or prayed less were more likely to drop out of the study, the proposed association could be inflated. Thus, we compared the 59 individuals who dropped out with the 643 who completed all measures at both time points. Participants who dropped out did not differ on Time 1 prayer, $F(699)<1, p>.05$, or on Time 1 alcohol consumption, $F(700)=3.18, p>.05$. This suggests that people who prayed less or drank more were not more likely to drop out of the study.

Prayer and total alcohol consumption analysis.

Cross-lagged stability model. We tested our hypotheses using structural equation modeling with Amos 7.0. Significant crosslagged effects reflect the presence of a relationship beyond that which can be accounted for by the stability of the constructs and the magnitude of their association at Time 1. The parameter estimates obtained for the cross-lagged stability model are shown in Figure 1. (Because this is a fully saturated model without any degrees of freedom, estimates of model fit do not provide meaningful information.) Our initial model included the control variables age, sex, and social desirability. However, both age and sex were not significantly related to either variable at Time 2; including them did not alter the final results. Thus, in the final model, we included only social desirability as a control variable. As hypothesized, the cross-lagged relation from Time 1 prayer frequency to Time 2 alcohol consumption was significant $(\beta=-.11, p<.01)$, even when controlling for social desirability. The path from initial alcohol consumption to later prayer frequency was not significant $(\beta=-.01, n s)$, contrary to any suggestion that alcohol consumption affects prayer. For full results, see Figure 1.

Nonrecursive model. To examine possible bidirectional or synchronous effects between prayer and alcohol consumption, we estimated a nonrecursive model (see Figure 2). For a synchronous effects model to be empirically identified, several conditions need to be satisfied. The present model satisfies these conditions in that earlier measures of prayer and alcohol consumption are presumed to be predetermined variables and thereby uncorrelated with the disturbance terms in both Time 2 equations, and both cross-lagged effects are constrained to be zero. This analysis yielded results that are consistent with those obtained in the cross-lagged stability model. The path from Time 2 prayer frequency to Time 2 alcohol consumption was significant $(\beta=-.12, p<.01)$, but the path from alcohol consumption to prayer frequency was not significant $(\beta=-.05, n s)$.

Table 2

Summary of Hierarchical Regression Analysis for Variables Predicting Total Problems Relating to Drinking Behavior $(N=828)$

\begin{tabular}{lrrrr}
\hline \multicolumn{1}{c}{ Variable } & \multicolumn{1}{c}{ SE B } & $\beta$ & $p$ \\
\hline Step 1 & & & & \\
Sex & -0.03 & 0.07 & -.01 & .67 \\
Age & 0.05 & 0.02 & .12 & .00 \\
$\quad$ Social desirability & -0.08 & 0.01 & -.21 & .00 \\
Step 2 & & & & \\
$\quad$ Prayer frequency & -0.04 & 0.01 & -.20 & .00 \\
\hline
\end{tabular}

Note. $R^{2}=.07$ for Step $1(p<.01) ; \Delta R^{2}=.04$ for Step $2(p<.01)$. Sex was coded so that $1=$ male and $2=$ female. 


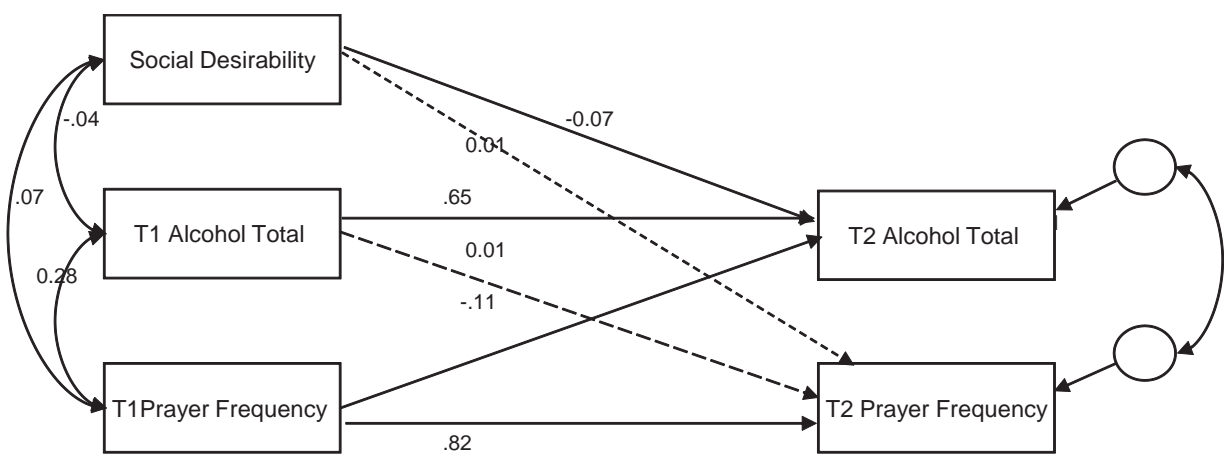

Figure 1. Cross-lagged stability model for prayer and alcohol consumption. - - - = Path was not significant.

The above results are consistent with the view that praying influences alcohol consumption, but that one's level of alcohol consumption does not influence the level of prayer. This is an important finding because it suggests the direction of effects in the relation between prayer and alcohol consumption and that prayer may be important in reducing alcohol consumption. Of course, experimental methods are needed to determine causality.

Prayer and problem drinking behavior analysis.

Cross-lagged stability model. Again, our initial model included the control variables age, sex, and social desirability. However, this time both age and social desirability were not significantly related to either variable at Time 2; including them did not alter the final results. Thus, in the final model, we included only sex as a control variable. As hypothesized, the cross-lagged relation from Time 1 prayer frequency to Time 2 problematic drinking was significant $(\beta=-.07, p<.05)$, even when controlling for sex. Also consistent with our prediction, the path from initial problematic drinking to later prayer frequency was not significant $(\beta=$ $-.01, n s)$. For full results, see Figure 3.

Nonrecursive model. We again examined possible bidirectional or synchronous effects between prayer and alcohol consumption using a nonrecursive model (see Figure 4). This analysis yielded results that were consistent with those obtained in the cross-lagged stability model as the path from Time 2 prayer frequency to Time 2 problematic drinking was significant $(\beta=$ $-.09, p<.01$ ), but the path from problematic drinking to prayer frequency was not significant $(\beta=-.01, n s)$. For full results, see Figure 4.

\section{Discussion}

Consistent with hypotheses, greater prayer frequency was related to both a decrease in total amount of alcohol consumption and problems related to alcohol consumption over a 3-month period. In addition, initial alcohol consumption or problems with alcohol did not predict prayer frequency 3 months later, suggesting a unidirectional relationship between these variables.

Yet, one important limitation of Studies 1 and 2 is that one cannot disentangle prayer behavior from overall religiosity; thus, we cannot be certain whether prayer is serving as a proxy for religiosity or whether there is something unique about prayer for predicting alcohol consumption and problematic drinking. A high intercorrelation of religious measures is a common problem in religious research (e.g., Gorsuch, 1984). An experimental design could remedy this limitation because random assignment of individuals to condition should distribute more or less religious individuals equally (or relatively so) between conditions, precluding religiosity as a third-variable explanation. One way to further preclude religiosity as an alternative explanation would be to exclusively select from a religious pool of participants and then randomly assign some to pray and others to perform a control activity. Holding religiosity constant through this type of design would further preclude it as an alternative explanation for the findings of Studies 1 and 2.

\section{Study 3}

Study 3 examined whether the relationship between prayer and alcohol consumption is a causal one using an experimental design. To enhance the likely effectiveness of the manipulation and to preclude religiosity from functioning as a third-variable explanation for our findings, we selected only participants who were at least somewhat religious. This allowed us to test whether religiosity was driving our prior findings, or whether there is something unique about prayer's effect on alcohol consumption. We hypothesized that participants randomly assigned to pray every day for 4

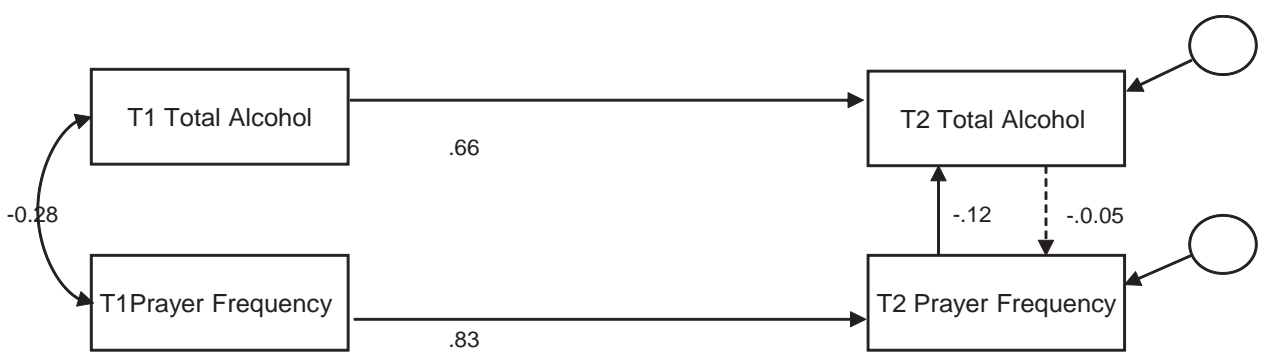

Figure 2. Nonrecursive model for prayer and alcohol consumption. - - - = Path was not significant. 


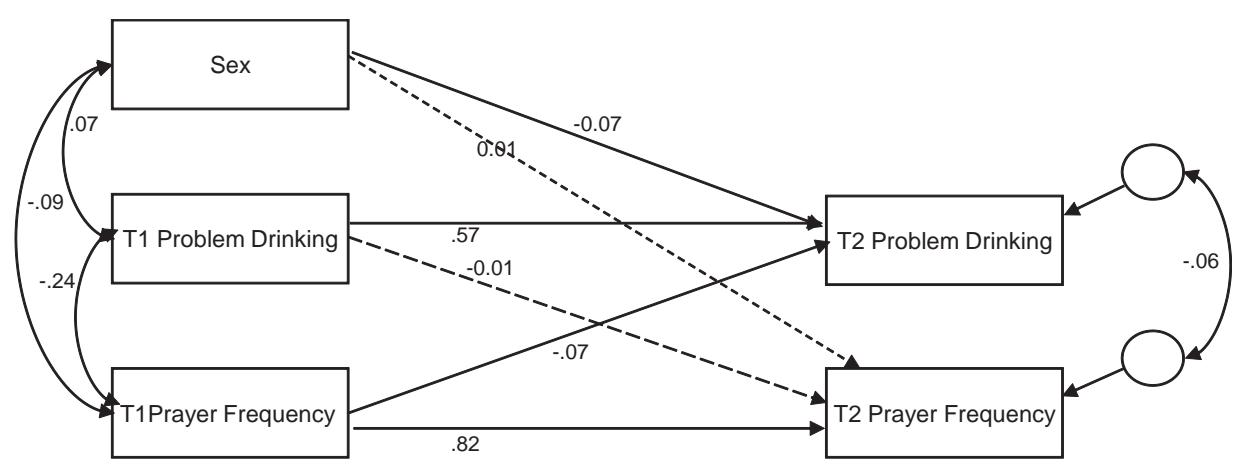

Figure 3. Cross-lagged stability model for prayer and problematic drinking. Sex was coded so that $1=$ male and 2 = female. - - = Path was not significant.

weeks would report lower alcohol consumption than those assigned to nonprayer conditions, even when controlling for initial alcohol consumption.

\section{Method}

Participants. During recruitment for the study, we invited only those who reported at least a minimal level of previous prayer (i.e., everyone who did not respond strongly disagree to the questions "I pray daily" and "I pray before I go to sleep") to filter out those who may have been uncomfortable with praying daily, which excluded about $25 \%$ of potential participants. Participants who did not meet these criteria were given an opportunity to participate in a study that did not involve prayer. The present study included 151 undergraduates who participated for extra credit. However, 28 participants who completed the measure at Time 1 dropped out of the study by Time 2. Also, when asked, "How seriously did you think about and write about your life experiences?" six participants responded almost never or less frequently than sometimes and were therefore dropped from the analysis.

Thus, the final sample included 117 undergraduates (102 women) who ranged in age from 18 to 28 years, with a median age of 19. Participants were 4\% Jewish, 22\% Protestant, 31\% Catholic, $1 \%$ Mormon, and $42 \%$ other (most of which were likely some form of Protestant, but prefer a different label, e.g., Baptist). Also, all the study participants reported being in a romantic relationship, the rationale for which was relevant to a broader study.

\section{Measures.}

Prayer. Initial prayer frequency was again assessed with the item "I pray daily." We thought it would be important to control for initial prayer frequency in subsequent analyses because of the potential differential effect of the manipulation on someone who prays frequently versus occasionally.

Alcohol consumption index. We used the same alcohol consumption index as in the first two studies; however, we adapted the items to reflect drinking during the prior week rather than the entire month (i.e., "In the last 7 days, on how many days did you have a drink containing alcohol?" multiplied by "How many drinks containing alcohol did you have on a typical day when you were drinking?"). We did not include the problematic drinking behavior measure in the current studies because it asks for report of problems related to drinking in a 4-month period, and therefore our 1-month journal study was not long enough to account for variance in such a measure. However, alcohol consumption was highly correlated with problematic drinking behavior in Study 1, $r(822)=.56, p<.001$, and Study 2, $r(700)=.54, p<.001$, which suggests total alcohol consumption is a strong predictor of problematic drinking behavior.

Participation in activity. Participants were asked one question to gauge their level of participation in the activity: "How often have you completed the writing activity that you were assigned?" on a scale from 1 (almost never) to 7 (all the time).

Procedure. All participants completed a battery of pretest measures that included those relevant to the current study. Then, participants were randomly assigned to one of four conditions and were instructed that they would need to complete their assigned activity every day and keep a log of how many minutes they engaged in their activity each day. Participants were also required to $\log$ on to an online journal twice a week, and each time they

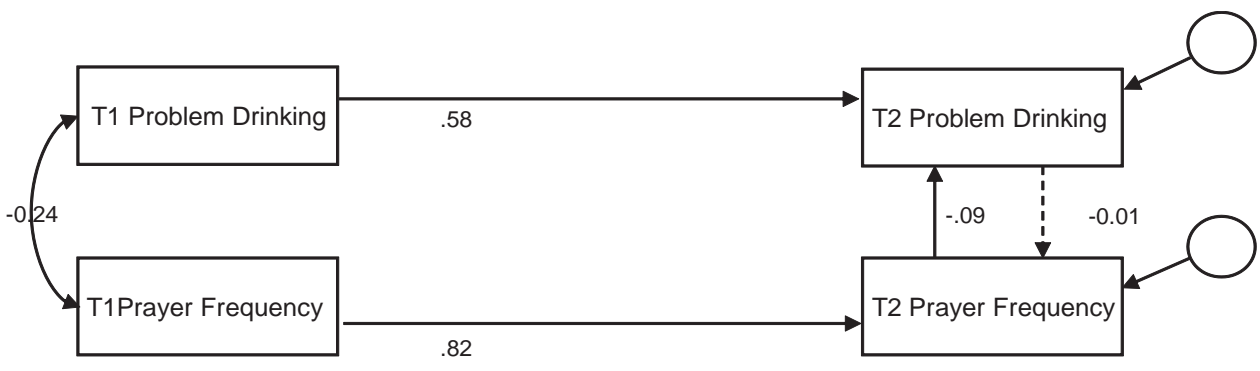

Figure 4. Nonrecursive model for prayer and problematic drinking. - - - = Path was not significant. 
logged in, they would report how many minutes they spent engaging in their assigned activity for the 3 days prior. In addition, they then actually spent some time engaging in and writing about their assigned activity to increase their overall compliance. They were instructed that they would lose extra credit points for missing these online sessions; therefore, compliance was quite high over the 4-week span of the study: Sixty-two percent of participants completed $100 \%$ of the sessions and $82 \%$ of participants completed at least $80 \%$ of the sessions. Nearly everyone included in the analysis completed at least $80 \%$ of the sessions, because most of the people who dropped out of the study before the follow-up also did not complete the journal entries.

Prayer conditions. The current study was part of a broader study that assessed the unique effects of praying for one's partner on certain relationship variables. Thus, those in the prayer for partner condition were given various relationship topics on which to focus their prayers each week. For example, participants were given the following instructions: "For the next four weeks, you have been assigned to pray for the well-being of your romantic relationship. Every Monday and Thursday you will receive a new relationship theme on which you will focus your prayers for the duration of 3-4 days until you receive the next theme. The prayer theme from now until Monday afternoon will be on love." These participants were then given an example of a prayer on love and then instructed to say such a prayer and then to pray such a prayer every day until they received a new prayer theme.

A second prayer condition comprised undirected prayer. In this condition, participants were not given any direction other than to pray daily and record what they prayed about. We had no theoretical rationale to suspect that the type of prayer (whether it was on relationships or undirected) would make a difference in terms of their effect on alcohol consumption. And indeed, the adjusted mean score of the Time 2 alcohol consumption of the prayer for partner condition was $2.65(S D=3.99)$ and the mean of the undirected prayer was $1.55(S D=3.17)$, controlling for Time 1 alcohol consumption, which was not a significant difference, $F(55)=1.53, p=.22$. We therefore combined these two conditions to create prayer versus nonprayer comparison conditions. Sixty-one participants were assigned to this condition (10 men, 51 women).

Control conditions. The relationship control group participants were instructed to write about the same relationship topics as used in the prayer condition and to think about these topics daily. The neutral control group participants were instructed to pay close attention to their daily activities each day and then to write about what happened to them. The adjusted mean score of the Time 2 alcohol consumption of the neutral condition was 5.13 ( $S D=$ $6.55)$, and the mean of the relationship enhancement condition was 3.67 ( $S D=5.48)$, controlling for Time 1 alcohol consumption, which was not a significant difference, $F(1,50)=1.65$, $p=.21$, so they were combined to create a nonprayer comparison condition. Fifty-six participants were assigned to this condition (5 men and 51 women). By chance, slightly more men were assigned to the prayer group (10) than to the control group (5). Thus, we controlled for sex in all the subsequent analyses to ensure that this was not having an unforeseen impact on our findings.

\section{Results}

Attrition and engagement. Twenty-eight participants who completed the measure at Time 1 failed to complete measures at Time 2 . To be sure that attrition was not artificially inflating our results (such that heavy drinkers dropped out more frequently), we compared Time 1 alcohol consumption scores of those who dropped out with those who remained in the study and found no differences between the groups, $F(147)=0.38, p>.05$. Also, to rule out the possibility that participants in the prayer conditions may have taken their assigned activity more seriously than those in the other conditions, we compared across conditions and found no significant differences between groups in level of engagement, $F(1,115)=0.50, p>.05$.

Prayer and alcohol consumption. We hypothesized that increasing the frequency with which participants prayed would decrease the amount of alcohol they drank. Analysis of covariance (ANCOVA) revealed a significant main effect for condition even when controlling for initial prayer frequency, initial drinking scores, sex, and engagement in study activities, $F(1,111)=5.82$, $p<.05, \eta_{\mathrm{p}}^{2}=.05$. Those in the prayer condition drank slightly more than half of the total amount of alcoholic drinks $(M=2.41$, $S D=3.62)$ as those in the control condition $(M=4.20, S D=$ 6.04; all means adjusted for covariates).

\section{Discussion}

Consistent with our hypothesis, the results of Study 3 demonstrate a causal relationship between prayer frequency and alcohol consumption, with prayer reducing drinking by about $50 \%$. Furthermore, through random assignment to condition and by using participants who did not deny engaging in spiritual or religious behavior, we showed that prayer has a unique effect on drinking behavior above and beyond spitituality and religiosity. This finding is particularly notable given that participants assigned to the control condition also reported some level of praying behavior at pretest, which should have made it more difficult to detect any differences between groups. To our knowledge, no prior research has experimentally tested the effects of praying on one's social behavior (although experimental studies have been done on the effect of one person's prayer on the physical health of another; for a review, see Masters \& Spielmans, 2007). One possible limitation to the current study is that we included only participants who were currently in a romantic relationship. It could be that people in relationships react differently to prayer or have drinking patterns different from those not in a romantic relationship. Thus, in Study 4 we recruited a sample that was not currently involved in a romantic relationship to determine whether the effects of prayer would replicate in a different sample.

\section{Study 4}

The objective of Study 4 was to determine whether the effect of prayer on alcohol use would replicate in another sample. Because involvement in a romantic relationship is associated with less risk-taking behavior (Braithwaite, Delevi, \& Fincham, in press), this study included only individuals who were not currently in a romantic relationship. We hypothesized that relationship status would not change the effect of prayer on alcohol use, but that 
prayer would affect alcohol use in a similar way as in Study 3, which examined only participants in romantic relationships. We used the same criterion from Study 3 to exclude those who were not comfortable with prayer.

\section{Method}

Participants. This study included 172 undergraduates who participated in the study for extra credit. Twelve participants from this sample were dropped for not taking the study seriously (following the criteria established in Study 3), and 45 did not complete the follow-up measures and were not included in the final analysis. Thus, 115 (94 women) participants ranging in age from 18 to 22 years, with a median age of 19 , were included in the analysis. Participants were 5\% Jewish, 28\% Protestant, 36\% Catholic, and $31 \%$ other (we suspect that most of these were actually Protestant, but preferred a different label).

\section{Measures.}

Prayer. Initial prayer frequency was again assessed the item "I pray daily."

Alcohol consumption index. We used the same alcohol consumption index as in Study 3.

Participation in activity. Participants were again asked one question to gauge their level of participation in the activity: "How often have you completed the writing activity that you were assigned?" on a scale from 1 (almost never) to 7 (all the time).

Procedure. All participants completed a battery of pretest measures that included those relevant to the current study. They were then randomly assigned to one of four conditions and were instructed that they would need to complete their assigned activity every day and keep a log of how many minutes they engaged in their activity each day. Again, participants were required to log on to an online journal twice a week to report their log and provide written descriptions about their assigned activity. The study lasted 4 weeks.

Prayer conditions. This study was part of a broader study that examined the effect of praying for several people on mental health outcomes. Therefore, those in the prayer for others condition were instructed to select five friends or family members to pray for every day for 4 weeks and to report about what they prayed about for each of these individuals in an online journal twice a week, whereas those assigned to the undirected prayer condition were simply instructed to pray every day and report what they prayed for. The adjusted mean score of the Time 2 alcohol consumption of the prayer for others condition was $2.37(S D=2.90)$ and the mean of the undirected prayer was $3.44(S D=6.78)$, controlling for Time 1 alcohol consumption, which was not a significant difference, $F(1,46)=0.83, p=.37$, so they were combined to create a single prayer condition. Fifty-two participants were assigned to this condition (9 men and 43 women).

Control conditions. Participants assigned to the relationship control condition were instructed to think daily about positive aspects of five friends or family members and to write about their thoughts twice a week in an online journal. The neutral control group participants were instructed to pay close attention to their daily activities each day and then to write about what happened to them. The adjusted mean score of the Time 2 alcohol consumption of the relationship control condition was $4.26(S D=6.86)$, and the mean of the neutral condition was $5.12(S D=7.40)$, controlling for Time 1 alcohol consumption, which was not a significant difference, $F(1,57)=0.31, p=.58$, so they were combined to create a single control condition. Sixty-three participants were assigned to this condition ( 12 men and 51 women). This time, also by chance, slightly more men were assigned to the control group (12) than to the prayer group (9). Thus, we again controlled for sex in all the subsequent analyses.

\section{Results}

Attrition and engagement. As previously noted, 45 participants completed the measures at Time 1 but failed to complete them at Time 2. We again compared the Time 1 alcohol consumption scores to ensure that people who drank more initially were not disproportionately dropping out. There were no differences between the groups, $t(158)=0.07, p=.95$. Twelve participants were dropped because they acknowledged that they did not take their assigned activity seriously. To rule out the possibility that participants in the prayer conditions may have taken their assigned activity more seriously than those in the other conditions, we compared across conditions and found no significant differences between groups in level of engagement, $F(3,111)=0.83, p>.05$. Thus, 115 participants were included in the final analysis.

Prayer and alcohol consumption. We hypothesized that the results from Study 3 would be replicated, namely, that those who prayed would drink less alcohol. Again, ANCOVA revealed a significant main effect for condition even when controlling for initial prayer frequency, initial alcohol consumption scores, sex, and degree of participation in assigned activity, $F(1,109)=4.53$, $p<.05, \eta_{\mathrm{p}}^{2}=.04$. Consistent with Study 3, those in the prayer condition again drank slightly more than half of the total amount of alcohol $(M=2.89, S D=5.22)$ as those in the control condition ( $M=4.74, S D=7.14$; all means were adjusted for covariates).

\section{General Discussion}

We hypothesized that there would be a negative relationship between prayer frequency and alcohol consumption; in a series of four studies, we found this to be the case. In Study 1, we used a cross-sectional design and found that prayer frequency was related to alcohol consumption and problematic drinking behavior even when controlling for sex, age, and social desirability. Study 2 used a longitudinal design to test whether this relationship would persist over time, and found that Time 1 prayer frequency predicted Time 2 alcohol consumption and Time 2 problematic drinking behavior even when controlling for baseline scores of these measures, sex, age, and social desirability. Furthermore, cross-lagged stability models showed that this relationship did not work in the opposite direction, providing some evidence for a unidirectional relationship between the variables from prayer to alcohol consumption.

Finally, in Studies 3 and 4, we used experimental methods to test whether the relationship between prayer frequency and alcohol consumption was causal. In both studies, we found that participants assigned to pray every day for 4 weeks drank about half as much alcohol at the conclusion of the study as control participants, even when controlling for baseline drinking level, initial prayer frequency, and level of participation. Thus, in all four studies prayer was associated with less drinking. The diversification of methods we employed also provides valuable confidence that our findings are not an artifact of any one approach. 
We now discuss these potential mechanisms in greater detail, perhaps to generate testable ideas for future research. Specifically, we focus on how prayer may reduce the motivation to turn to alcohol for enhancement and conformity or social motives by discussing some recent research on prayer and healthy relationship functioning. We then provide a more in-depth discussion of prayer's role in reducing motives to drink for coping purposes by discussing Pargament's (1997) theoretical model and Baumeister's (1991) proposal for escaping the "burden of the self."

\section{Prayer and Relationship Functioning}

It may be that prayer is negatively related to alcohol consumption inasmuch as enhanced relationship functioning reduces the need to use alcohol to cope. Also, perhaps if social relationships are stronger, one would not need to rely on alcohol to be more sociable or to have a good time at social gatherings. Some recent research demonstrates that prayer may be beneficial to relationships. A recent article documents both a cross-sectional and longitudinal relationship between prayer for partner and relationship satisfaction (Fincham, Beach, Lambert, Stillman, \& Braithwaite, 2008). Furthermore, Fincham, Lambert, and Beach (2009) conducted a journal study in which participants were instructed to pray for their romantic partner every day for 4 weeks and found that those who prayed for their partner reported lower levels of infidelity during this period than those who thought daily positive thoughts about their partner. The benefits of prayer appear to extend beyond romantic relationships, however. Participants randomly assigned to pray for their most important interpersonal relationship reported greater willingness to forgive this person than those assigned to think about a positive joint activity with their important relationship partner (Lambert, Fincham, Stillman, Graham, \& Beach, 2009). Although research in this area has only recently begun, there is some indication that prayer may benefit relationships, and this may be one mechanism through which prayer reduces alcohol consumption.

\section{Prayer and the Burden of the Self}

Another possible path by which prayer may reduce coping motives is through helping the individual escape from the "burden of the self." Baumeister (1991) proposed that people abuse alcohol for the same reason they perform spiritual behaviors: They seek to escape from the "burden of the self." Self-awareness can become a burden, particularly when people have high expectations for themselves or when they feel that their high expectations may exceed their capabilities. According to Baumeister, placing high demands on the self is especially common in Western culture. Thus, people seek refuge from awareness of the self (with the accompanying obligations and failures) in pursuits such as heavy drinking and spirituality. Both alcohol and spirituality offer an unburdening of the self, such that one has temporary relief from the pressure to achieve and the disappointment of failure. This burden is likely to be experienced acutely among emerging adults as they transition from late adolescence into adulthood, a transition that is likely accompanied by increased self-awareness as this age group experiments with new roles. An extension of Baumeister's thesis is that increasing one method of unburdening the self (or coping) through prayer renders the other (alcohol) less useful and less necessary. This is another hypothesis that could be tested empirically. Thus, we propose two mechanisms for the relationship between prayer and alcohol consumption to be tested by future research: Prayer may facilitate positive social relationships, thus reducing social motives to drink; and prayer facilitates collaborative coping, thereby reducing use of alcohol as a coping mechanism.

\section{Limitation and Future Directions}

The current studies are limited to young adult college students, and perhaps prayer would not have the same effect among more diverse participants. However, given the high rates of drinking among college students, the social pressures to drink in college, and the deleterious effects drinking has on them, this seemed to be an important group to target for such research. Nonetheless, future research should examine the effect of prayer among several different types of samples in several different settings.

It also bears mentioning that the experimental findings were obtained among a sample of people who pray at least sometimes. Thus, it cannot be inferred that the results of Studies 3 and 4 generalize beyond those who have an existing belief in prayer. However, future research on this topic should include additional covariates (e.g., personality or socioeconomic status) that may be particularly relevant to religious individuals to minimize concerns of generalizability. Conversely, studying only those who prayed at least sometimes should mitigate the potential problem of participants not praying with sincerity, although this could still be a limitation for the experimental studies. Also, both Studies 3 and 4 were part of a broader study about the influence of prayer on relationships; thus, the content of the prayers of half of the participants were directed at relationship partners. We do not suspect that the content of the prayers affected the results; indeed, our analysis showed that there was no differential effect on alcohol consumption on the basis of prayer content. However, this does limit the generalizability of our findings.

In addition, it should be noted that Studies 3 and 4 reflect not only prayer but prayer plus journaling. It could be that prayer by itself may not yield the same results, which could be determined by future research. Finally, finding out that the study was on prayer through the informed consent process may have introduced some bias in the reporting; however, we attempted to address this possibility by controlling for initial levels of prayer completed before participants found out about their assigned condition.

\section{Conclusion}

By randomly assigning some religious participants to increase the frequency of their prayers and others to participate in a control activity, we were able to rule out religiosity as a third-variable explanation and show that prayer had a unique effect on alcohol consumption. This has implications not only for alcohol consumption, but for the scientific study of religion more generally as experimental methods have not been widely used in this area of study. Perhaps experimentally examining prayer may be an appropriate means by which typical obstacles to research on religiosity (e.g., self-selection bias or the alternative explanation of religious social networks) may be overcome. 
In four studies, we used a variety of methods to demonstrate that prayer frequency was negatively related to alcohol consumption using a cross-sectional design (Study 1), a longitudinal design (Study 2), and an experimental design (Studies 3 and 4). The results of these studies indicate that praying does seem to have an effect on alcohol consumption.

\section{References}

Abbey, A. (2002). Alcohol-related sexual assault: A common problem among college students. Journal of Studies on Alcohol, 63, 118-128.

Arasteh, K., Des Jarlais, D. C., \& Perlis, T. E. (2008). Alcohol and HIV sexual risk behaviors among injection drug users. Drug and Alcohol Dependence, 95, 54-61.

Baier, C. J., \& Wright, B. R. E. (2001). If you love me, keep my commandments: A meta-analysis of the effect of religion on crime. Journal of Research in Crime and Delinquency, 38, 3-21.

Baumeister, R. F. (1991). Escaping the self: Alcoholism, spirituality, masochism, and other flights from the burden of selfhood. New York: Basic Books.

Braithwaite, S., Delevi, R., \& Fincham, F. D. (2010). Romantic relationships and the physical and mental health of college students. Personal Relationships. Advance online publication: doi: 10.1111/j.14756811.2010.01248.x

Benda, B. B., Pope, S. K., \& Kelleher, K. J. (2006). Church attendance or religiousness: Their relationship to adolescents' uses of alcohol, other drugs, and delinquency. Alcoholism Treatment Quarterly, 24, 75-87.

Burger, W. R., \& Youkeles, M. (2000). Human services in contemporary America. Pacific Grove, CA: Brooks/Cole.

Carver, C. S., Scheier, M. F., \& Weintraub, J. K. (1989). Assessing coping strategies: A theoretically based approach. Journal of Personality and Social Psychology, 56, 267-283.

Chappel, J. N., \& DuPont, R. L. (1999). Twelve-step and mutual help programs for addictive disorders. The Psychiatric Clinics of North America, 22, 425-445.

Cooper, M. L. (1994). Motivations for alcohol use among adolescents: Development and validation of a four-factor model. Psychological Assessment, 6, 117-128.

Cooper, M. L. (2002). Alcohol use and risky sexual behavior among college students and youth: Evaluating the evidence. Journal of Studies on Alcohol, 63, 101-117.

Dawson, D. A., \& Room, R. (2000). Towards agreement on ways to measure and report drinking patterns and alcohol-related problems in adult general population surveys: The Skarpo Conference overview. Journal of Substance Abuse, 12, 1-21.

Dull, V. T., \& Skokan, L. A. (1995). A cognitive model of religion's influence on health. Journal of Social Issues, 51, 49-64.

Ellison, C. G., \& George, L. K. (1994). Religious involvement, social ties, and social support in a southeastern community. Journal for the Scientific Study of Religion, 33, 46-61.

Fenzel, L. M. (2005, March/April). Multivariate analyses of predictors of heavy episodic drinking and drinking-related problems among college students. Journal of College Student Development, 46, 126-140.

Fincham, F. D., Beach, S. R. H., Lambert, N. M., Stillman, T. F., \& Braithwaite, S. R. (2008). Spiritual behaviors and relationship satisfaction: A critical analysis of the role of prayer. Journal of Social and Clinical Psychology, 27, 362-388.

Fincham, F. D., Lambert, N. M., \& Beach, S. R. H. (in press). Faith and unfaithfulness: Can praying for your partner reduce infidelity? Journal of Personality and Social Psychology.

Folkman, S., Lazarus, R. S., Dunkel-Schetter, C., DeLongis, A., \& Gruen, R. J. (1986). Dynamics of a stressful encounter: Cognitive appraisal, coping, and encounter outcomes. Journal of Personality and Social Psychology, 50, 992-1003.
Gartner, J., Larson, D. B., \& Allen, G. (1991). Religious commitment and mental health: A review of the empirical literature. Journal of Psychology and Theology, 19, 6-25.

Gorsuch, R. L. (1984). The boon and bane of investigating religion. American Psychologist, 39, 228-236.

Gorsuch, R. L. (1995). Religious aspects of substance abuse and recovery. Journal of Social Issues, 51, 65-83.

Graham, S. M., Fincham, F. D., \& Lambert, N. M. (2009). Getting drunk and sleeping around: Problem drinking and its association with infidelity. Manuscript submitted for publication.

Hadaway, C. K., Marler, P. L., \& Chavez, M. (1993). What the polls don't show: A closer look at U.S. church attendance. American Sociological Review, 58, 741-752.

Hilton, M. E. (1991). The demographic distribution of drinking problems in 1984. In W. B. Clark \& M. E. Hilton (Eds.), Alcohol in America: Drinking practices and problems (pp. 87-101). Albany: State University of New York Press.

Hingson, R., Heeren, T., Winter, M., \& Wechsler, H. (2003). Early age of first drunkenness as a factor in college students' unplanned and unprotected sex attributable to drinking. Pediatrics, 111, 34-41.

Hingson, R., Heeren, T., Winter, M., \& Wechsler, H. (2005). Magnitude of alcohol-related mortality and morbidity among U.S. college students ages 18-24: Changes from 1998 to 2001. Annual Review of Public Health, 26, 259-279.

Humphreys, K., \& Gifford, E. (2006). Religion, spirituality, and the troublesome use of substances. In W. R. Miller \& K. M. Carroll (Eds.), Rethinking substance abuse: What the science shows, and what we should do about it (pp. 257-274). New York: Guilford Press.

Johnson, T. J., Sheets, V. L., \& Kristeller, J. L. (2008). Identifying mediators of the relationship between religiousness/spirituality and alcohol use. Journal of Studies on Alcohol and Drugs, 69, 160-170.

Johnston, L. D., O’Malley, P. M., Bachman, J. G., \& Schulenberg, J. E. (2007). Monitoring the Future National Survey results on drug use, 1975-2006: Vol. 2. College students and adults ages 19-45. Bethesda, MD: National Institute on Drug Abuse.

Joiner, T., Perez, M., \& Walker, R. (2002). Playing devil's advocate: Why not conclude that the relation of religiosity to mental health reduces to mundane mediators? Psychological Inquiry, 13, 214-216.

Jones, S. E., Oeltmann, J., Wilson, T. W., Brener, N. D., \& Hill, C. V. (2001). Binge drinking among undergraduate college students in the United States: Implications for other substance use. Journal of American College Health, 50, 33-38.

Kapner, D. A. (2008). Alcohol and other drugs on campus: The scope of the problem. Newton, MA: The Higher Education Center for Alcohol and Other Drug Abuse and Violence.

Koenig, H. G., George, L. K., Meador, K. G., Blazer, D. G., \& Ford, S. M. (1994). Religious practices and alcoholism in a southern adult population. Hospital and Community Psychiatry, 45, 225-231.

Koenig, H. G., McCollough, M. E., \& Larson, D. B. (Eds.). (2001). Handbook of religion and health. New York: Oxford University Press.

Lambert, N. M., Fincham, F. D., Stillman, T. F., Graham, S. M., \& Beach, S. R. H. (2010). Motivating change in relationships: Can prayer increase forgiveness? Psychological Science, 21, 126-132.

Lawson, K., Reesor, K. A., Keefe, F. J., \& Turner, J. A. (1990). Dimensions of pain-related cognitive coping: Cross-validation of the factor structure of the Coping Strategy Questionnaire. Pain, 43, 195-204.

Masters, K. S., \& Spielmans, G. I. (2007). Prayer and health: Review, meta-analysis, and research agenda. Journal of Behavioral Medicine, 30 , 329-338.

Mathias, A. S., \& Turrentine, C. G. (2003). An intimate look at contraception and alcohol consumption. NASPA Journal, 40(4), 105-123.

McCullough, M. E., \& Larson, D. B. (1999). Prayer. In W. R. Miller (Ed.), Integrating spirituality into treatment: Resources for practitioners (pp. 85-110). Washington, DC: American Psychological Association. 
Miller, W. R. (1998). Researching the spiritual dimensions of alcohol and other drug problems. Addiction, 93, 979-990.

Miller, W. R., Forcechimes, A., O'Leary, M. J., \& LaNoue, M. D. (2008). Spiritual direction in addiction treatment: Two clinical trials. Journal of Substance Abuse Treatment, 35, 434-442.

Mohler-Kuo, M., Dowdall, G. W., \& Koss, M. P. (2005). Correlates of rape while intoxicated in a national sample of college women. Journal of Studies on Alcohol, 65, 37-45.

O'Malley, P. M., \& Johnston, L. D. (2002). Epidemiology of alcohol and other drug use among American college students. Journal of Studies on Alcohol, 63(2), 23-39.

O'Hare, T. (1997). Measuring problem drinking in first time offenders: Development and validation of the College Alcohol Problem Scale (CAPS). Journal of Substance Abuse Treatment, 14, 383-387.

Ouimette, P. C., Finney, J. W., \& Moos, R. H. (1997). Twelve-step and cognitive-behavioral treatment for substance abuse: A comparison of treatment effectiveness. Journal of Consulting and Clinical Psychology, $65,230-240$

Pargament, K. I. (1997). The psychology of religion and coping: Theory, research, practice. New York: Guilford Press.

Park, C. L., \& Levenson, M. R. (2002). Drinking to cope among college students: Prevalence, problems and coping processes. Journal of Studies on Alcohol, 63, 486-497.

Parker, G. B., \& Brown, L. B. (1982). Coping behaviors that mediate between life events and depression. Archives of General Psychiatry, 39, 1386-1391.

Perkins, H. W. (2002). Surveying the damage: A review of research on consequences of alcohol misuse in college populations. Journal of Studies on Alcohol, 63, 91-100.

Piedmont, R. L. (2004). Spiritual transcendence as a predictor of psychosocial outcome from an outpatient substance abuse program. Psychology of Addictive Behaviors, 18, 213-222.

Regnerus, M. D. (2003). Linked lives, faith, and behavior: Intergenera- tional religious influence on adolescent delinquency. Journal for the Scientific Study of Religion, 42, 189-203.

Reynolds, W. M. (1982). Development of reliable and valid short forms of the Marlowe-Crowne Social Desirability Scale. Journal of Clinical Psychology, 38, 119-125.

Taylor, R. J., Chatters, L. M., \& Levin, J. S. (2004). Religion in the lives of African Americans: Social, psychological, and health perspectives. Thousand Oaks, CA: Sage.

Townsend, M., Kladder, V., Ayele, H., \& Mulligan, T. (2002). Systematic review of clinical trials examining the effects of religion on health. Southern Medical Journal, 95, 1429-1434.

U.S. Religious Landscape Survey. (2008). Summary of key findings. Retrieved from http://religions.pewforum.org/pdf/report2religiouslandscape-study-key-findings.pdf

Walker, S. R., Tonigan, J. S., Miller, W. R., Corner, S., \& Kahlich, L. (1997). Intercessory prayer in the treatment of alcohol abuse and dependence: A pilot investigation. Alternative Therapies in Health and Medicine, 3, 79-86.

Wechsler, H., \& Nelson, T. F. (2008). What we have learned from the Harvard School of Public Health College Alcohol Study: Focusing attention on college student alcohol consumption and the environmental conditions that promote it. Journal of Studies on Alcohol and Drugs, 69, $1-10$.

Weitzman, E. R., Nelson, T. F., \& Wechsler, H. (2003). Taking up binge drinking in college: The influences of person, social group, and environment. Journal of Adolescent Health, 32, 26-35.

Worthington, E. L., Jr. (Ed.). (1993). Psychotherapy and religious values. Grand Rapids, MI: Baker.

Received March 21, 2009

Revision received November 22, 2009

Accepted November 25, 2009

\section{E-Mail Notification of Your Latest Issue Online!}

Would you like to know when the next issue of your favorite APA journal will be available online? This service is now available to you. Sign up at http://notify.apa.org/ and you will be notified by e-mail when issues of interest to you become available! 